\title{
NOS EMBARAÇOS DA INTERDIÇÃO: DESVELANDO DISCURSOS ACERCA DA MULHER COM A MATEMÁTICA
}

\section{IN THE STRIPS OF INTERDICTION: UNVEILING SPEECHES ABOUT WOMEN WITH MATHEMATICS}

\author{
CORDEIRO, Jane Cleide de Almeida ${ }^{1}$ \\ BARBOZA, Pedro Lúcio
}

\begin{abstract}
RESUMO
A História mostra uma baixa presença feminina na construção da matemática. Vários fatores contribuíram para tal questão, entre eles, os históricos e culturais. Muitos mitos foram se moldando ao longo dos anos acerca da relação da mulher com a matemática, um dos mais conhecidos é o de que "homens são naturalmente melhores que mulheres em matemática e raciocínio lógico". O principal objetivo deste estudo é identificar e refletir sobre os mitos acerca da relação da mulher com a matemática. Para a obtenção dos dados, aplicamos um questionário a vinte e cinco alunos do $3^{\circ}$ ano do ensino médio, de uma escola pública. Esta é uma pesquisa de cunho explicativo, assim como qualitativo e para análise dos dados consideramos como base principal o conceito de procedimentos de exclusão interdito de Foucault. Os dados apontam, na maioria dos discursos dos participantes, explicações que podem ser consideradas mitos acerca da participação da mulher na matemática ou procedimentos de exclusão interditos.
\end{abstract}

Palavras-Chave: Gêneros; Mitos; Mulheres; Matemática; Procedimentos de Exclusão Interditos.

\begin{abstract}
History shows a low female presence in the construction of mathematics. Several factors contributed to this issue, among them, the historical and cultural. Many myths have been molded over the years about the relationship of women to mathematics, one of the best known is that "men are naturally better than women in mathematics and logical reasoning". The main objective of this study is to identify and reflect on the myths about the relationship of women with mathematics. To obtain the data, we applied a questionnaire to twenty-five students from the 3rd year of high school, from a public school. This is an explanatory as well as qualitative research and

1 Universidade Estadual da Paraíba - UEPB / Programa de Pós-Graduação em Ensino de Ciências e Educação Matemática - PPGECEM. São João do Cariri, PB, Brasil. ORCID: https://orcid.org/0000-0003-1773-2032. email: janecleideac@hotmail.com

2 Universidade Estadual da Paraíba - UEPB / Programa de Pós-Graduação em Ensino de Ciências e Educação Matemática - PPGECEM. Campina Grande, PB, Brasil. ORCID: https://orcid.org/0000-0002-4118-8201 email: plbcg@yahoo.com.br
\end{abstract}


DOI: $10.12957 / \mathrm{e}-\mathrm{mosaicos} .2021 .53641$

for data analysis we consider Foucault's concept of prohibited exclusion procedures as the main basis. The data point out, in most of the participants' speeches, explanations that can be considered myths about women's participation in mathematics or prohibited exclusion procedures.

KeYwoRDS: Genres; Myths; Women; Mathematics; Interdiction Exclusion Procedures.

\section{INTRODUÇÃO}

Quando olhamos para a História, percebemos uma baixa presença feminina na construção da matemática. Uma questão apregoada na sociedade para explicar a presença limitada da mulher na matemática, seria a desculpa da mesma ser possivelmente incapaz intelectualmente para atuar nessa área.

Muitos mitos foram sendo moldados ao longo dos anos acerca da relação da mulher com a matemática. Segundo Fernandes (2006, p.70), "pode-se dizer que o mito é uma intuição compreensiva da realidade, que não necessita de provas para ser aceita. É uma forma espontânea do ser humano situar-se no mundo".

No Dicio (Dicionário online de português) encontramos que mito se refere a "algo ou alguém cuja existência não é real ou não pode ser comprovada". Alves (2005, p.70), nos alerta para os perigos que acompanham os mitos ao afirmar: "E todo mito é perigoso, porque ele induz o comportamento e inibe o pensamento".

Carmo e Ferraz, 2012, p.55) destacam um dos principais mitos referentes a esse assunto, quando citam: "homens são naturalmente melhores que mulheres em matemática e raciocínio lógico". Esse discurso que busca por afirmar ser intrínseco ao homem um raciocínio superior ao da mulher em relação à matemática, circula nos ouvidos das crianças desde muito cedo, no seio da família, assim como em escolas e mídias em geral, suscitando assim um efeito danoso na formação e diferenciação dos papéis sexuais, e moldando atitudes ante a matemática que repercutirão nas escolhas e no desempenho profissional.

Não podemos deixar de mencionar a desvantagem que outrora a mulher teve no que diz respeito ao acesso ao ensino, pois para a mesma era permitido aprender apenas o essencial para desenvolver os trabalhos do lar e cuidado dos filhos, "levando-se em conta que apenas os homens tinham o direito a frequentar a escola. $E$ sem o direito ao conhecimento, as mulheres não podiam defender adequadamente, senão a maior, uma das maiores aspirações humanas, que é a própria liberdade" (CARVALHO; FERREIRA; PENEIREIRO, 2016, p. 573).

Algumas poucas mulheres no passado romperam com essas barreiras, usando de artifícios para se equiparar no campo da matemática, e um exemplo foi Émilie du Châtelet. 
DOI: $10.12957 / \mathrm{e}-\mathrm{mosaicos} .2021 .53641$

"Sua estratégia, incomum para os padrões da época, de vestir-se com roupa masculina nos encontros com seus colegas homens nas cafeterias parisienses, tinha, claramente, 0 propósito de se nivelar com os mesmos, na defesa de seus argumentos" (CARVALHO; FERREIRA; PENEIREIRO, 2016, p. 581).

Em diversos campos profissionais ainda perduram os mitos alimentados nos atos de contratação, no salário diferenciado, ou até mesmo na divisão do trabalho. Segundo o site Observatório de Gênero do Governo Federal (BRASIL,2014), o Brasil apresenta um dos maiores níveis de disparidade salarial. No país, os homens ganham aproximadamente $30 \%$ a mais que as mulheres de mesma idade e nível de instrução.

Um dos campos profissionais que sofre preocupantes reflexos, que perduram ao longo dos anos, é o campo educacional, onde ainda é limitada a participação do sexo feminino em áreas ligadas a matemática.

Carvalho, Ferreira e Penereiro (2016) relatam o quão desafiador tem sido aos educadores e psicopedagogos, entender as razões pelas quais a opção pela matemática e por áreas afins, é de forma predominante composta por estudantes do gênero masculino.

Estamos de acordo com Fernandes (2006, p.72) quando afirma que mesmo com os avanços em termos de acesso ao estudo e a concursos, "ainda perdura a divisão de papeis sexuais e de gênero moldados culturalmente, que impede as mulheres de assumir posições profissionais de prestígio no campo científico."

As desigualdades de gênero, os preconceitos e os mitos existentes, "no ensino da matemática (sem base científica) têm forte influência na pequena participação das mulheres neste campo de conhecimento" (FERNANDES, 2006, P. 72). São influências tão relevantes que têm o poder de criar ou modificar atitudes diferenciadas entre homens e mulheres, muitas vezes acabam refletindo na atitude em relação à matemática, refletem não apenas em relação à matemática, mas também no futuro profissional.

Diante das influências, e como já mencionado aqui o poder da sociedade de ditar princípios, nos deparamos com um cenário onde até mesmo a própria mulher começa a duvidar de suas capacidades cognitivas. O contexto social the induz de forma muito discreta e camuflada a aceitar certas violências simbólicas e interdições tanto nos atos de contratação, como em salários diferenciados, e até nos simples impulsos para áreas tradicionalmente femininas, que acabam por fazer a mesma aceitar naturalmente tais abusos e até crer realmente haver uma vantagem masculina em determinadas áreas.

Essa ideia pode ser comprovada através da pesquisa de Souza e Fonseca (2008), "Para a maioria delas (58\%), o ato de fazer contas representa sempre uma dificuldade, quando não uma absoluta impossibilidade. O inverso acontece com o público masculino".

Tomamos como base principal para análise de dados da nossa pesquisa, o conceito de procedimentos de exclusão interdito de Foucault: 
DOI: $10.12957 /$ e-mosaicos.2021.53641

É claro que sabemos, numa sociedade como a nossa, da existência de procedimentos de exclusão. 0 mais evidente, o mais familiar também, é o interdito. Temos consciência de que não temos o direito de dizer o que nos apetece, que não podemos falar de tudo em qualquer circunstância, que quem quer que seja, finalmente, não pode falar do que quer que seja (FOUCAULT, 1971, p. 2).

Por meio desse conceito, observamos a existência de alguns discursos exclusivos proferidos de forma interdita. Mas o que seria afinal esta interdição? Segundo Foucault (1971), Procedimentos Interditos, ou por diversas vezes "não ditos", são jogos do pensamento e da língua que disfarçam uma possível exclusão. "O discurso manifesto não passaria, afinal de contas, da presença repressiva do ele diz; e esse não-dito seria um vazio minando, do interior, tudo que se diz" (FOUCAULT, 2008, p.28).

$\mathrm{O}$ interdito e o não dito, neste contexto, caminham na mesma direção de limitar o discurso a fins desejados. "O interdito é um impedimento estrutural e estruturante ao dizer completo, impedindo que se diga tudo, e, por isso mesmo, permitindo que se diga algo. $\mathrm{O}$ dizer é sempre faltante, é sempre meio-dito, dito no meio, dito pela metade: interdito" (TFOUNI, 2013, p.40).

Assim sendo, consideramos que o interdito esteja em meio ao dito, trazendo consigo de forma sutil, essências de exclusões, por diversas vezes despercebidas tanto pelo orador quanto pelo ouvinte, sendo transmitidos naturalmente, acima de qualquer suspeita.

"O enunciado não é assombrado pela presença secreta do não-dito, das significações ocultas, das repressões; ao contrário, a maneira pela qual os elementos ocultos funcionam e podem ser restituídos depende da própria modalidade enunciativa" (FOUCAULT, 2008, p.125).

O conceito de procedimentos de exclusão interditos nos dá base para pesquisar uma possível ausência de incentivo ao gênero feminino de forma interdita para escolha profissional em Licenciatura Matemática, que tem se mostrado muito discretamente pela sociedade em geral até os dias atuais.

\section{ALgUnS eStudos REALIzAdos NA ÁREA}

Por muito tempo acreditamos que as mulheres não tinham predisposição biológica para as ciências exatas, após muitos estudos acredita-se que tal fenômeno é de origem social. Dentre estes estudos, considerando necessário observar os processos socioculturais no interior dos quais se articulam tais afirmações, Saboya (2013) faz uma breve revisão teórica relacionando Ciência e Tecnologia e Relações de Gênero, considerando alguns 
DOI: $10.12957 /$ e-mosaicos.2021.53641

estudos nacionais e internacionais sobre o tema, destacando ainda a escassez de produções acadêmicas que entrecruzam essas duas áreas. O autor afirma "que as mulheres ainda são minoria, nesse campo construído histórica e culturalmente sob o domínio de valores e representações masculinas" (SABOYA, 2013, p. 21) e destaca que as dificuldades enfrentadas pelas mulheres nesta área são enormes.

Na pesquisa Cavalari (2007), com objetivo de mapear a presença feminina nos cursos e Departamentos de Matemática e Matemática Aplicada da USP (São Paulo e São Carlos), UNESP (Rio Claro e São José do Rio Preto), FFCL de Araraquara e UNICAMP, comprova as limitações na área, mostrando que quanto mais alto o posto/nível da carreira acadêmica, menor é a presença feminina. Seus resultados mostram que as mulheres são mais numerosas entre os professores assistentes doutores que entre os professores titulares, somente quatro professoras obtiveram o título de professoras titulares nestas instituições.

Cavalari (2010) também apresenta um trabalho com o intuito de oferecer alguns subsídios para o professor abordar em suas atividades educativas, a temática mulher na matemática, onde constam biografias das matemáticas Maria Gaetana Agnesi, Sophia Kovalevskya e Emmy Noether, a autora afirma que, apesar destas mulheres trazerem contribuições significativas para a construção do conhecimento matemático, permanecem desconhecidas da maioria dos estudantes de nossas escolas e universidades.

Sobre a opção por matemática, Carvalho, Ferreira e Penereiro (2016) relatam as causas e consequências históricas da discriminação de gênero na Educação, Ensino e Pesquisa associadas à matemática, assim como a forma como as mulheres romperam as imposições de seu tempo, conquistando notoriedade. Porém, ressaltam que "Tem sido desafiador aos Educadores e Psicopedagogos, justamente por isto, entender as razões pelas quais a opção pela Matemática e por áreas afins, predomina de forma exageradamente destacada entre estudantes do gênero masculino" (CARVALHO, FERREIRA E PENEREIRO, 2016, p.592).

Silva (2017) afirma haver uma forte desigualdade entre homens e mulheres no campo das ciências exatas em uma investigação sobre a participação feminina no Instituto Nacional de Matemática Pura e Aplicada (IMPA) e no Centro Brasileiro de Pesquisas Físicas (CBPF). A autora se baseia na análise quantitativa atual de pesquisadores por gênero, em suas diferentes categorias e na estrutura administrativa dessas instituições. A investigação apontou que a presença nas duas instituições do gênero masculino predomina nos cargos mais elevados. Silva (2017) afirma que na divisão sexual do trabalho, as mulheres estão sujeitas ao que chama de "teto de vidro", que são as barreiras invisíveis que as impedem de ascender na área da pesquisa nesses campos. O trabalho também faz alusão à necessidade de políticas que contribuam para mudanças no campo de atuação profissional das mulheres na pesquisa científica. 
DOI: $10.12957 /$ e-mosaicos.2021.53641

Oliveira (2012) apresenta um posicionamento diferente de Silva (2017) quando afirma que atualmente a sub-representação das mulheres nas Ciências Exatas e no campo profissional tem outros motivos além da questão do gênero, como a questão da escolha e as opções de horas parciais de trabalho para equilíbrio profissional/familiar. Oliveira (2012) considera o fato de as mulheres estarem presentes em vários níveis de estudo, Licenciatura, Bacharelado e Mestrado, porém em menor número. Sua pesquisa considerou a discriminação existente em duas vertentes. A primeira é a histórica, onde as mulheres eram submissas e quase não tinham acesso ao estudo, e a segunda vertente é nos dias atuais, onde a sub-representação é uma questão de escolha e não mais de gênero.

Os estudos de Nascimento (2011) cunham a presença de algumas mulheres no campo científico da matemática, ressaltando a discriminação que havia no passado quanto ao acesso da mulher a esta área. Nascimento (2011) destaca mulheres que desafiaram os costumes sociais, agregando importantes conhecimentos ao campo da matemática. Theano, Hipátia, Emmy Noether e professora Santana, são alguns dos nomes que aparecem em suas pesquisas, entre muitas outras. Com este trabalho o autor homenageou as docentes da área, assim como ofereceu subsídios para os demais pesquisadores, afirmando que cada história de vida desta enriquece a formação docente, e aponta belos caminhos trilhados os quais precisamos andar com mais frequência.

Baseado no desinteresse, sentimento de fracasso, e incapacidade para compreender e resolver problemas matemáticos por parte dos alunos na maioria das escolas públicas, Gontijo (2007) em uma pesquisa busca aprofundar a compreensão sobre o fenômeno da criatividade em Matemática mediante o gênero, "os resultados indicam que não há diferenças significativas entre alunos dos gêneros masculino e feminino quanto às medidas de criatividade no Teste Torrance do pensamento criativo" (GONTIJO, 2007, p.7).

Com o objetivo de apresentar os problemas relacionados à manutenção das grandes diferenças que se estabelecem entre homens e mulheres no que diz respeito à inclusão nos diversos campos profissionais e científico, Olinto (2011) descreve os mecanismos que levam à segregação das mulheres, que contribuem para tais problemas. A autora apresenta dados sobre a participação de homens e mulheres entre os recursos humanos de ciência e tecnologia dos bolsistas de pesquisa do CNPq. Suas análises apresentaram que os três primeiros níveis de bolsas se mostram proporcionais em relação ao gênero. Entretanto, a concessão a bolsas de produtividade sugere a atuação de mecanismos, que a autora classifica como segregação horizontal e segregação vertical, os quais estabelecem barreiras enfrentadas pelas mulheres no campo científico, deixando a carreira das pesquisadoras do sexo feminino em desvantagem. 
DOI: $10.12957 / \mathrm{e}-\mathrm{mosaicos} .2021 .53641$

\section{Metodologia}

Nesta pesquisa, cujo objetivo é identificar e refletir sobre os mitos acerca da relação da mulher com a matemática, para a obtenção dos dados foi utilizado um questionário aberto com oito perguntas e uma pergunta com possibilidade de múltipla escolha, aplicado a 25 alunos do $3^{\circ}$ ano do ensino médio de uma escola pública, sendo 10 do sexo masculino e 15 do sexo feminino.

Esta pesquisa se mostra na forma explicativa, pois segundo Costa e Costa (2011) é do tipo que "busca esclarecer que fatores contribuem de alguma forma para a ocorrência de algum fenômeno" (p.36), sendo este o fato de termos ainda nos dias atuais pouca representatividade da mulher no campo da matemática.

Também a identificamos como sendo de cunho qualitativo, pois trata com maior relevância das relações sociais, nas esferas da vida, assim como a dissolução de desigualdades sociais, dentro de uma diversidade de ambientes, subcultura, estilos e formas de vida (FLICK, 2009).

\section{ANÁLISE E DISCUSSÃO DOS DADOS}

Organizamos o questionário de forma que os respondentes do sexo feminino são identificados com a letra " $F$ " seguida de um número de ordem, assim como os respondentes do sexo masculinos com a letra " $\mathrm{M}$ " e o seu respectivo número de ordem.

Em uma sociedade marcada por tantas conflagrações na luta pelo reconhecimento ao gênero feminino no âmbito profissional, acreditamos na possibilidade de encontrar atualmente discursos discriminatórios em relação à mulher com a matemática, todavia, expor claramente opiniões desta esfera de forma franca torna-se complexo, justamente pela trajetória de lutas e conquistas do gênero feminino.

Na primeira questão, os participantes foram indagados com relação à preferência por professores de matemática em relação ao gênero. Os resultados nos mostraram que a maior parte dos participantes não tem preferências, porém $20 \%$ dos participantes do sexo masculino preferem estudar com professores nesta disciplina, ao passo que nenhum prefere professoras. Vejamos alguns discursos justificando a preferência:

Masculino, porque é mais fácil de aprender (M8).

Matemática gosto mais dos professores masculinos porque explicam melhor na minha opinião (M9).

Acredito que do sexo masculino, até porque nunca tive professoras do sexo feminino, então fica difícil julgar (F10). 
DOI: $10.12957 / \mathrm{e}-\mathrm{mosaicos} .2021 .53641$

Do sexo masculino, porque na minha instituição escolar, existem mais profissionais masculinos nessa área, e as vezes que estudei com mulheres que ensinam essa matéria, eu não compreendia direito as aulas (F11).

Observemos que o participante $M(8)$ diz ter preferência por estudar com professores do sexo masculino justificando apenas ser mais fácil de aprender. Este discurso não deixa claro o motivo específico que o levou a esta conclusão, isto nos deixa a indagar a existência de uma exclusão interdita mediada pela falta de clareza. O conceito de "mito" já mencionado por meio de Fernandes (2006), nos dá base para afirmar que este tipo de exclusão alimenta o mito, pois o participante tomou algo como verdadeiro sem nenhum tipo de justificação de que aprender matemática com professores do sexo masculino seria mais fácil.

Acerca de procedimentos de exclusão como o mencionado por $M(8)$, Foucault (1996) afirma: "Ora esta vontade de verdade, tal como os outros sistemas de exclusão, apoia-se numa base institucional: ela é ao mesmo tempo reforçada e conduzida por toda uma espessura de práticas como a pedagogia" (FOUCAULT, 1996, p. 17).

Esse sistema de forças verdadeiras não se molda ao redor das evidências científicas, mas são geralmente sustentadas e partilhadas entre instituições, laços familiares, grupos sociais ou políticos, que exercem uma determinada influência sobre a sociedade, constituindo assim discursos com o poder para deslegitimar os demais que se oponham. "O discurso, aparentemente, pode nem ser nada de por aí além, mas no entanto, os interditos que o atingem, revelam, cedo, de imediato, o seu vínculo ao desejo e o poder" (FOUCAULT, 1971, p.2). Sendo assim, não passam de procedimentos de exclusão que se apresentam de forma interdita com domínio de rotular vozes como verdadeiras ou falsas.

De comum modo o participante $\mathrm{M}(9)$, ao optar por professores do sexo masculino exclui a opção do gênero feminino justificando que em sua opinião os homens explicam melhor o conteúdo, isso nos deixa a indagar o leitor se ficou interdito que para ele as mulheres não ensinam tão bem o quanto os homens, nesta matéria.

A participante $F(10)$ afirmou acreditar ter sua preferência pelo gênero masculino, porém em sua justificativa alega que "nunca" teve professoras do sexo feminino, e ainda admite ser difícil julgar dada a tal situação. Esse pode ser considerado um Procedimento De Exclusão Interdito mediado pelo mito de homens ensinarem melhor a matemática, pois ao fato de "nunca" ter havido experiências com professoras do sexo feminino não torna difícil, mas sim impossível julgar uma determinada preferência, onde tais julgamentos em geral, são aceitos pelo "senso comum", noções comumente admitidas pelos indivíduos. 0 mesmo poderia ter ocorrido a participante $F(11)$ por alegar que a instituição dispunha de mais professores do sexo masculino, porém esta, de diferente modo complementou 
DOI: $10.12957 / \mathrm{e}-\mathrm{mosaicos} .2021 .53641$

afirmando que as vezes que estudou com professoras mulheres, ela não compreendeu corretamente o conteúdo.

Nos próximos discursos observamos falas aparentemente livres de procedimentos de exclusão, pois as mesmas, não tiveram experiências com professoras do sexo feminino, e para tal, preferiram não optar por uma determinada preferência, mesmo tendo sido alegado um comodismo ao costume de sempre haver professores do sexo masculino nessa disciplina.

Não sei como especificar, na maioria das vezes estudei com professor do sexo masculino (F2).

Tive uma professora de matemática no $6^{\circ}$ ano, não me lembro bem do seu ensino, portanto sou acostumada com professores homens na disciplina de matemática (F8).

Foucault (1996, p. 46) nos alerta para o efeito de discursos sobre as mulheres e homens, pois "determina para os sujeitos que falam, ao mesmo tempo, propriedades singulares e papéis preestabelecidos", definindo assim lugares sociais, que refletem o comodismo de se sentir 'acostumado' a tais disposições. As participantes se punham acostumadas ao fato de não haver muitas mulheres professoras de matemática, e alimentam o mito de haver campos profissionais direcionados mediante o gênero.

Os alunos foram questionados na segunda pergunta, se seriam capazes de ressaltar diferenças entre professores homens e professoras mulheres de matemática no ato de ensinar. $77,77 \%$ dos participantes masculinos não ressaltou diferença alguma, os demais ressaltaram poucas diferenças, ao passo que, as participantes femininas que não ressaltaram diferença alguma foram $46,66 \%$, e as demais poucas diferenças:

Geralmente, homens são conhecidos por ocuparem áreas de exatas pelo fato de serem considerados mais racionais e severos, ao contrário do que se pensa das mulheres, que são mais emotivas (F8).

Sim, porque as mulheres têm mais o cuidado ao explicar, e os homens são mais diretos, objetivos e que ajuda a entendermos rápido o assunto, mas também acho que as mulheres são mais capacitadas, e que estão vindo a abranger nessa área de ensino (F11).

A mulher tem mais paciência de ensinar e tem mais prática de lidar com os alunos. Já o homem tem temperamento mais forte, ou seja, mais rígido nos ensinos (F15). 
DOI: $10.12957 / \mathrm{e}-\mathrm{mosaicos} .2021 .53641$

Podemos observar no discurso das participantes $F(8), F(11)$ e $F(15)$ que a sociedade promove um Procedimento de Exclusão Interdito ao induzir que os homens são mais racionais, severos, diretos, rígidos, objetivos, rápidos e com temperamento forte, onde tais características seriam supostamente requisitos importantes para a área de exatas, e as mesmas não seriam propriamente femininas, tornando-as inadequadas para esta área e alimentado assim os mais diversos mitos ligados a características particulares.

O que percebemos ao longo destes discursos é que muitas vezes não passam de meras repetições: Aquilo que me foi ensinado, eu reproduzo quase mecânica ou automaticamente, sem uma avaliação mais apurada de minhas ideologias em relação ao tema. Configura-se como uma "prodigiosa maquinaria destinada a excluir todos aqueles que, ponto a ponto, em nossa história, procuraram contornar essa vontade de verdade e colocá-la em questão contra a verdade" (FOUCAULT, 1971, p.5). O discurso permanece em um círculo de repetições e transmissões com pouco ou nada das intervenções criativas próprias de uma libertação ou reinvenção do discurso.

Junto a discursos como estes relacionados aos Procedimentos de Exclusão Interditos, caminham reflexões da ideia de poder compreender que as forças que produzem e multiplicam tais discursos sempre atendem a um grupo de interesses, não sendo assim de origens ingênuas.

Segundo Gomes e Torres (2017):

Independentemente de sua natureza, em toda sociedade, a produção de discursividade é, sobremaneira, alvo de procedimentos e mecanismos de modelagem e enquadramento. Controle, seleção, distribuição, organização, redistribuição, rarefação e repetição são exemplos visíveis de uma condução que parece estar na fisiologia de toda e qualquer produção discursiva (GOMES; TORRES, 2017, p.63).

Quando perguntamos sobre o que pensam a respeito da mulher ensinando matemática. Destacamos dois trechos, aparentemente livres de pré-conceito ou discriminação:

Acho muito plausível mulheres atuando na área de Exatas, pois antigamente elas só faziam 'coisas de moças' e hoje em dia com muitas oportunidades surgindo para a mulher, elas podem ensinar bem a matemática e se igualar ao homem (F7) (grifo próprio).

Acho uma ideia até interessante, comparando as professoras de outras matérias, as mulheres tem maior paciência para ensinar (F10) (grifo próprio). 
DOI: $10.12957 / \mathrm{e}-\mathrm{mosaicos} .2021 .53641$

Podemos nos questionar se ao falar "elas podem ensinar matemática e se igualar ao homem", a participante $F(7)$, embora pareça livre de preconceitos, não estaria manifestando uma exclusão interdita, quando menciona que a mulher pode se igualar ao homem, neste caso, poderíamos entender que a participante deixou dito nas entrelinhas que os homens já estavam em "patamar" elevado no ato de ensinar a matemática, mas que as mulheres "poderiam" se igualar aos mesmos. De modo semelhante, a participante F(10) diz: "Acho uma ideia até interessante", esse trecho nos mostra o quanto ainda é forte o mito de que este campo é particular aos homens, e que a mulher pode sentir-se convidada a adentrá-lo, pelo fato de que comparou com professoras de outras matérias, e $\mathrm{o}$ ato de ensinar está ligado também às características maternas e/ou femininas, como a paciência foi citada pela participante.

Sobre estes discursos aparentemente libertos de todo ritual de exclusão, Foucault (2008) nos alerta para o que se encontra interdito quando afirma:

[...] gostaria de mostrar, por meio de exemplos precisos, que, analisando os próprios discursos, vemos se desfazerem os laços aparentemente tão fortes entre as palavras e as coisas, e destacar-se um conjunto de regras, próprias da prática discursiva. Essas regras definem não a existência muda de uma realidade, não o uso canônico de um vocabulário, mas o regime dos objetos" (FOUCAULT, 2008, p. 54-55).

Quando perguntamos em relação a acreditar que ainda exista preconceito ou falta de incentivo por parte dos professores, familiares e amigos para as mulheres optarem por cursos superiores que envolvam a matemática, obtivemos de $33,33 \%$ dos respondentes do gênero masculino a afirmação de que ainda existe, assim como, 66,66\% das respondentes do gênero feminino também afirmam. A seguir, alguns discursos que entendemos apresentar exclusões interditas e mitos relacionados à mulher no âmbito deste questionamento:

Ainda há esse preconceito, porque infelizmente a sociedade visualiza esta matéria como algo cansativo (F2) (grifo próprio).

Sim, pela matemática ser considerada uma matéria complicada e difícil de compreender, eles afirmam que as mulheres têm outras responsabilidades e não podem se dedicar apenas ao estudo (F10) (grifo próprio).

Percebemos nessas falas alguns mitos em relação à matemática como o fato de ser algo cansativo, complicado e difícil, que estabelecem uma imagem preconcebida de que pelos mesmos, a mulher esteja em desvantagem. Silva (2009) nos adverte quanto aos 
DOI: $10.12957 / \mathrm{e}-\mathrm{mosaicos} .2021 .53641$

perigos dos estereótipos e preconceitos e suas consequências relacionadas aos interditos sociais, quando afirma:

Estereótipos e preconceitos, ao comporem o conteúdo das representações sociais, ou seja, da maneira pela qual o senso comum aprende e confere sentido à realidade, são instrumentos utilíssimos na promoção os interditos sociais, na delimitação das fronteiras, sejam elas étnicas, religiosas, linguísticas, de gênero ou quaisquer outras (SILVA, 2009, p. 26).

Os participantes foram arguidos no sexto questionamento, sobre existir ou não uma tendência natural dos homens para a matemática e das mulheres para as ciências humanas. Os resultados mostram que $33,33 \%$ dos participantes masculinos e 46,66\% das participantes femininas acreditam haver sim essa tendência natural.

Não existe, a mulher pode ser tão boa, e as vezes melhor que o homem em qualquer curso (F7) (grifo próprio).

Sim, existe sim essa tendência, na minha opinião homem para matemática, e as mulheres para outras áreas da educação (M9).

Sim, porque a sociedade feminina é intitulada como sexo frágil, e_precisa estar em profissões que não exijam esforço físico e mental (F11) (grifo próprio).

Cordeiro (2014) ressalta sobre discursos como este da participante $F(7)$, que menciona que a mulher "poder ser tão boa quanto o homem" em matemática, e apenas "às vezes" melhor que eles, quando afirma:

Isto nos remete a refletir se as mulheres seriam mesmo tão boas o quanto os homens, ou se seriam os homens tão bons o quanto as mulheres, tendo em vista que, a ausência da mesma tenha sido única e exclusivamente pela falta de acesso ao conhecimento (CORDEIRO, 2014, p. 46).

Percebemos que ao colocar uma condição de que a mulher pode ser tão boa quanto o homem, a participante colocou de forma interdita que o homem já estaria em um escalão mais elevado quanto aos cálculos, e suas falas ficam ainda mais precisas quando afirma que apenas às vezes a mulher seria melhor que o homem em tal campo. São discursos como este que estabelecem uma categorização para o campo, onde a 
DOI: $10.12957 / \mathrm{e}-\mathrm{mosaicos} .2021 .53641$

mulher não faria parte deste composto de características essenciais, fazendo assim com que até as do próprio gênero se convençam disto e assim reproduzam discursos como este de forma interdita, porém que as discriminam, alimentam os mitos de que as mesmas não são bem vindas neste campo, fortalecendo as relações de poder que perpassam tais falas.

Tudo se passa como se os interditos, as barragens, as entradas e os limites do discurso tivessem sido dispostos de maneira a que, ao menos em parte, a proliferação do discurso seja dominada, de maneira a que a sua riqueza seja alijada da sua parte mais perigosa e que a sua desordem seja organizada segundo figuras que esquivam aquilo que é mais incontrolável (FOUCAULT, 1971, p.14).

Nos discursos de M9 e F11, não encontramos procedimentos de exclusão interditos "propriamente ditos", entretanto, os participantes apresentaram formas discriminatórias explicitas em seus discursos ao afirmarem que o homem tem uma tendência natural para a matemática e que a mulher devia se limitar a outras áreas, assim como ao mencionar a mulher como um suposto "sexo frágil", portanto não devia exercer funções que venham a requerer esforços físicos ou mentais. Esses discursos são mitos, pois não existe base científica para tais afirmações. Existe a possibilidade de reprodução deste tipo de discurso que colabora para a disseminação de rotulações, prejudicando assim não só uma pessoa em particular como também toda uma classe que se enquadre em tais rótulos.

Na questão da pesquisa direcionada para a indicação pessoal dos participantes sobre quais dos gêneros ensina melhor a matemática, baseado nos professores que teve em sua vida acadêmica até o presente momento. A opinião dos participantes masculinos que consideram que o gênero feminino ensina melhor a matemática foi de $22,22 \%$. As participantes do gênero feminino que acreditam que o mesmo ensina melhor a referida disciplina foi de $6,66 \%$.

O homem, porque é mais objetivo e direto (F11).

$\mathrm{O}$ homem, porque tive mais afinidade com professores homens, e ensinam melhor (M9).

Em todo o meu ensino na escola, só tive duas professoras mulheres, mas os que ensinaram melhor foram os homens (F7).

Observamos que, mesmo a pergunta sendo direcionada para todos os anos da vida acadêmica, isso incluindo os anos inicias do ensino fundamental, onde a maior parte dos 
DOI: $10.12957 / \mathrm{e}-\mathrm{mosaicos} .2021 .53641$

docentes são do sexo feminino, por ser o campo de atuação dos pedagogos e por estar na vertente oposta à matemática em questão da presença da mulher numericamente falando.

Ainda assim, e também levando-se em consideração as características já mencionadas de atenção, cuidado, paciência entre outras da mulher, as respostas ainda não foram positivas quanto ao gênero feminino ensinando matemática, onde apenas $6,66 \%$ das participantes femininas acreditam que seu gênero ensina melhor.

\section{CONSIDERAÇõES FINAIS}

Os participantes da pesquisa, em sua maioria, se amparam, principalmente, nos procedimentos de exclusão interditos. Encontramos também em alguns participantes discursos que indicam um posicionamento livre de preconceitos acerca da participação da mulher na matemática, é o caso, por exemplo, das participantes F7, F10 e F11, mas em outros momentos essas mesmas participantes também apresentam procedimentos de exclusão interditos ou falas discriminatórias.

A pesquisa mostra ainda haver necessidade de aprofundamentos do tema. Opções de pesquisas, por exemplo, sobre o discurso de alunos e professores podem ampliar o estudo desta temática, e pode ajudar a compreender melhor os efeitos causados pela presença e/ou ausência da mulher na área, detectando possíveis meios para a desconstrução da visão de que este seria um campo masculino, gerando mais conforto e interesse na mulher para com a matemática, e consequentemente um melhor equilíbrio na participação dos gêneros masculino e feminino.

Concluímos nossas reflexões com o pensamento de Silva (2009, p.25): "Todos esses procedimentos de exclusão/estigmatização desempenham um papel relevante para a dinâmica das relações sociais pelo fato de permitirem uma categorização dos grupos e indivíduos com base em preconceitos e estereótipos".

\section{REFERÊNCIAS}

ALVES, R. Filosofia da Ciência: introdução ao jogo e a suas regras, 9.ed. São Paulo, Loyola, p.221, 2005.

CARMO, J. S.; FERRAZ, A. C. T. Ansiedade relacionada à matemática e diferenças de gênero: uma análise da literatura. Psicologia da Educação, São Paulo, v.35, p.53-71, $2^{\circ}$ sem., 2012. Disponível: http://pepsic.bvsalud.org/pdf/psie/n35/n35a04.pdf Acesso 7 de agosto 2020. 
DOI: $10.12957 / \mathrm{e}-\mathrm{mosaicos} .2021 .53641$

CARVALHO, T. F.; FERREIRA, D. H. L.; PENEREIRO, J. C. Matemática, Mulheres e Mitos: causas e consequências históricas da discriminação de gênero. Educação Matemática e Pesquisa. São Paulo, v.18, n.2, p. 571-597, 2016. Disponível: https://revistas.pucsp.br/emp/article/view/21909/pdf Acesso 4 de junho 2020.

CAVALARI, M. F. A matemática é feminina? Um estudo histórico da presença da mulher em institutos de pesquisa em matemática do estado de são Paulo. 2007. $156 \mathrm{f}$. Dissertação de Mestrado- Universidade Estadual Paulista. Rio Claro-SP. 2007. Disponível: https://repositorio.unesp.br/handle/11449/91099 6 julho 2020.

CAVALARI, M. F. Mulheres matemáticas: presença feminina na docência no ensino superior de matemática das universidades estaduais paulistas-Brasil. Revista Brasileira de História da Matemática. São Paulo, v.10, n.19, p. 89-102, 2010. Disponível: http://www.rbhm.org.br/vo10-no19.html Acesso 5 de julho 2020.

CORDEIRO, J. C. A. A percepção dos alunos de licenciatura em Matemática na UEPB de Campina Grande quanto à presença da mulher no curso. 2014. $65 \mathrm{f}$. Trabalho de Conclusão de Curso Licenciatura em Matemática - Universidade Estadual da Paraíba, Campina Grande, 2014.2 Disponível em: http://dspace.bc.uepb.edu.br/jspui/handle/123456789/36/simple-search? filterquery=2014\&filtername=dateIssued\&filtertype=equals Acesso 10 Junho 2020.

COSTA, M. A. F.; COSTA, M. F. B. Projeto de pesquisa: entenda e faça. $2^{\mathrm{a}}$ ed. PetrópolisRJ, Vozes, p.140, 2011.

DICIO, Dicionário online de português. Disponível em: https://www.dicio.com.br/mito. Acesso em: 18 mai. de 2019.

FERNANDES, M. C. V. A inserção e vivência da mulher na docência de matemática: uma questão de gênero. 2006. 107 f. Dissertação de Mestrado - Programa de Pós-graduação em Educação, Universidade Federal da Paraíba, João Pessoa. 2006. Disponível em: https://repositorio.ufpb.br/jspui/bitstream/tede/4959/1/arquivototal.pdf Acesso 3 agosto 2020.

FLICK, U. Introdução a pesquisa científica. Tradução: Joice Elias Costa - $3^{a}$ ed. Porto Alegre: Artmed, p. 405, 2009.

FOUCAULT, M. Arqueologia do saber. 7a ed. Rio de Janeiro: Forense Universitária, p.238, 2008.

FOUCAULT, M. A ordem do discurso. 7a. ed. Tradução de Laura Fraga Sampaio. São Paulo: Loyola, 1996. 
DOI: $10.12957 / \mathrm{e}-\mathrm{mosaicos} .2021 .53641$

FOUCAULT, M. L'ordre du discours, Leçon Inaugurale au College de France prononcèe le 2 decembre 1970, Editions Gallimard, Paris, 1971.Tradução de Edmundo Cordeiro e António Bento.

GOMES, A. L.; TORRES, J. V. C. Nos labirintos do discurso: agendamento e procedimentos de exclusão nos títulos da Folha, Globo e Estadão. Comunicação e Inovação. v.18, n.36, p.62-72, jan./abr. 2017. Disponível em: file:///C:/Users/Pedro/Downloads/4021-14747-1PB\%20(1).pdf Acesso 18 de julho 2020.

GONTIJO, C. H. Relações entre criatividade, Criatividade em Matemática e motivação em Matemática de Alunos do Ensino Médio. 2007. 206 f. Tese apresentada para obtenção de Título de Doutor em Psicologia- Programa de Pós-graduação em Psicologia, Universidade de Brasília, Brasília. p. 79-86, 2007. Disponível em: https://repositorio.unb.br/handle/10482/2528 Acesso 18 de Junho 2020.

NASCIMENTO, J. B. Algumas Mulheres da História da Matemática. Reportagem: Novo Olhar Sobre a Matemática, Beira Rio, Ano. 26, no.93, p.67, abril de 2011. Disponível em: https://www.mathunion.org/fileadmin/CDC/cdc-uploads/CVgrantsIndividual/ mulheres.matematica.maio..13.pdf Acesso 8 de junho 2020.

OBSERVATÓRIO DE GÊNERO, Homens recebem salários 30\% maiores que as mulheres no Brasil. Disponível em: http://www.observatoriodegenero.gov.br/menu/noticias/homensrecebem-salarios-30-maiores-que-as-mulheres-no-brasil/ Acesso em: 13 set.2019.

OLINTO, G. A inclusão das mulheres nas carreiras de ciências e tecnologia no Brasil. Inc. Soc., Brasilia-DF, v.5, n.1, p.68-77, jul./dez.2011. Disponível em: https://www.google.com.br/search? newwindow $=1 \&$ sXsrf=ALeKk00bzay78XwhTalLYDjLmmfoiHyYNg \%3A1596993372043\&ei=XC8wX-SWAqm75OUPzOaGkAM\&q=OLINTO\%2C+G. + Acesso2 de junho 2020.

OLIVEIRA, C. M. A presença das mulheres nas ciências exatas. 2012. 71 f. Trabalho de Conclusão de Graduação em Licenciatura em Matemática - Faculdade de Engenharia de Guaratinguetá, Universidade Estadual Paulista, Guaratinguetá, 2012. Disponível em: https://repositorio.unesp.br/handle/11449/120256 Acesso 8 de maio 2020.

SABOYA, M.C.L. Relações de gênero, ciência e tecnologia: uma revisão da bibliografia nacional e internacional. Educação, Gestão e Sociedade, v.3, n.12, p.26 nov. 2013. Disponível em: https://www.gestaoesociedade.org/gestaoesociedade/issue/archive Acesso 25 Maio 2020. 
DOI: $10.12957 / \mathrm{e}-\mathrm{mosaicos} .2021 .53641$

SILVA, G. V. Desvio social, exclusão e estigmatização: notas para o estudo da "História dos marginais". Dimensões, UFES- Pós-Graduação em História, Espirito Santo-ES, v.23, p.17, 2009. Disponível em: https://periodicos.ufes.br/dimensoes/issue/view/220 Acesso 25 de julho 2020.

SILVA. M. G. E. S. A mulher pesquisadora e sua invisibilidade nos campos da matemática e da física. In: Seminário Internacional Fazendo Gênero 11 e $13^{\circ}$ Women's Worlds Congress, 2017, Florianópolis, Anais Eletrônicos. p. 13. ISSN 2179-510X. Disponível em: http://www.en.wwc2017.eventos.dype.com.br/resources/anais/1496849482_ARQUIVO_M ariaGabrielaESdaSilvaMM_FG.pdf Acesso 28 de maio 2020.

SOUZA, M. C. R. F.; FONSECA, M. C. F. Mulheres, homens e matemática: uma leitura a partir dos dados do Indicador Nacional de Alfabetismo Funcional, Educação e Pesquisa, São Paulo, v.34, n.3, p.511-526, 2008. Disponível em: https://www.scielo.br/pdf/ep/v34n3/v34n3a07.pdf Acesso 29 de julho 2020.

TFOUNI, F. E. V. Interdito e silêncio: análise de alguns enunciados. Ágora, Rio de Janeiro, v. 16, n. 1, p.39-56, jan./jun., 2013. Disponível em: https://www.scielo.br/pdf/agora/v16n1/v16n1a03.pdf acesso 12 julho 2020.

Recebido em 11 de agosto de 2020

Aceito em 26 de novembro de 2020

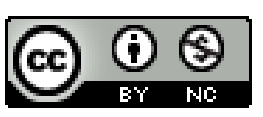

A e-Mosaicos Revista Multidisciplinar de Ensino, Pesquisa, Extensão e Cultura do Instituto de Aplicação Fernando Rodrigues da Silveira (CAp-UERJ) está disponibilizada sob uma Licença Creative Commons - Atribuição - NãoComercial 4.0 Internacional.

Os direitos autorais de todos os trabalhos publicados na revista pertencem ao(s) seu(s) autor(es) e coautor(es), com o direito de primeira publicação cedido à e-Mosaicos.

Os artigos publicados são de acesso público, de uso gratuito, com atribuição de autoria obrigatória, para aplicações de finalidade educacional e não-comercial, de acordo com o modelo de licenciamento Creative Commons adotado pela revista. 